\title{
Silent journey of a late lead pacemaker perforation
}

\author{
Luísa Gonçalves $\odot$, Inês Pires $\odot$, João Santos $\odot$, Joana Correia๑, Vanda Neto®, \\ Davide Moreira $\odot$, Inês Almeida $\odot$, António Costa $\odot$, Costa Cabral $\odot$ \\ Department of Cardiology, Centro Hospitalar Tondela-Viseu, Viseu, Portugal
}

An 83-year-old male with frailty and ischemic cardiomyopathy underwent uncomplicated pacemaker implantation with passive fixation atrial lead and active fixation ventricular lead (VL) (Fig. 1A), for paroxysmal high-degree atrioventricular block. Follow-up ensued with normal pacemaker function at 3 months, but intermittent loss of ventricular capture was perceived 1 year later. Echocardiography excluded pericardial effusion. On fluoroscopy-guided surgical review, VL appeared dislocated and surrounded by fibrous adhesions, so it was abandoned and a new VL was implanted (Fig. 1B). Two years after surgical review, cardiac computed tomography (CT) was performed due to unrelated motive and disclosed lead perforation (Fig. 1C; Suppl. Video 1). Precise perforation time was hard to determine. Late lead perforation (LLP) was retrospectively assumed on the basis of VL malfunctioning at 1 year plus active fixation and elderly as predisposing factors. Conservative treatment was chosen based on the absence of symptoms or pericardial effusion, stable condition, and incidental finding as a silent perforation. One year after CT diagnosis, at the age of 87, the patient remained asymptomatic but ultimately died from medical complications during hospitalization for a right femur fracture.

Late lead perforation occurs in $0.1 \%$ of implantations when a lead exceeds cardiac contour 1 month after implantation. Incidental LLP has a 6\% prevalence in CT studies and should be considered, even many years after implantation. The imbalance and complex interaction of forces determines LLP when lead tip prevails over myocardium counterforce. Lead positioning in a vulnerable region, thinner and less compliant leads, bipolar leads, and excessive loop or tension are other predisposing factors. Treatment depends on the timing of perforation, presence of symptoms, pericardial effusion or extracardiac damage. Measuring risk and benefit, asymptomatic and stable patients with prohibitive surgical risk can be managed conservatively.

Conflict of interest: None declared

Address for correspondence: Dr. Luísa Gonçalves, Department of Cardiology, Centro Hospitalar Tondela-Viseu, Avenida Rei D.Duarte, Viseu, Portugal 3504-509, tel: +35 1934120142, e-mail: malvar.luisa@gmail.com

Received: 28.11.2020 Accepted: 12.06 .2020

This article is available in open access under Creative Common Attribution-Non-Commercial-No Derivatives 4.0 International (CC BY-NC-ND 4.0) license, allowing to download articles and share them with others as long as they credit the authors and the publisher, but without permission to change them in any way or use them commercially. 


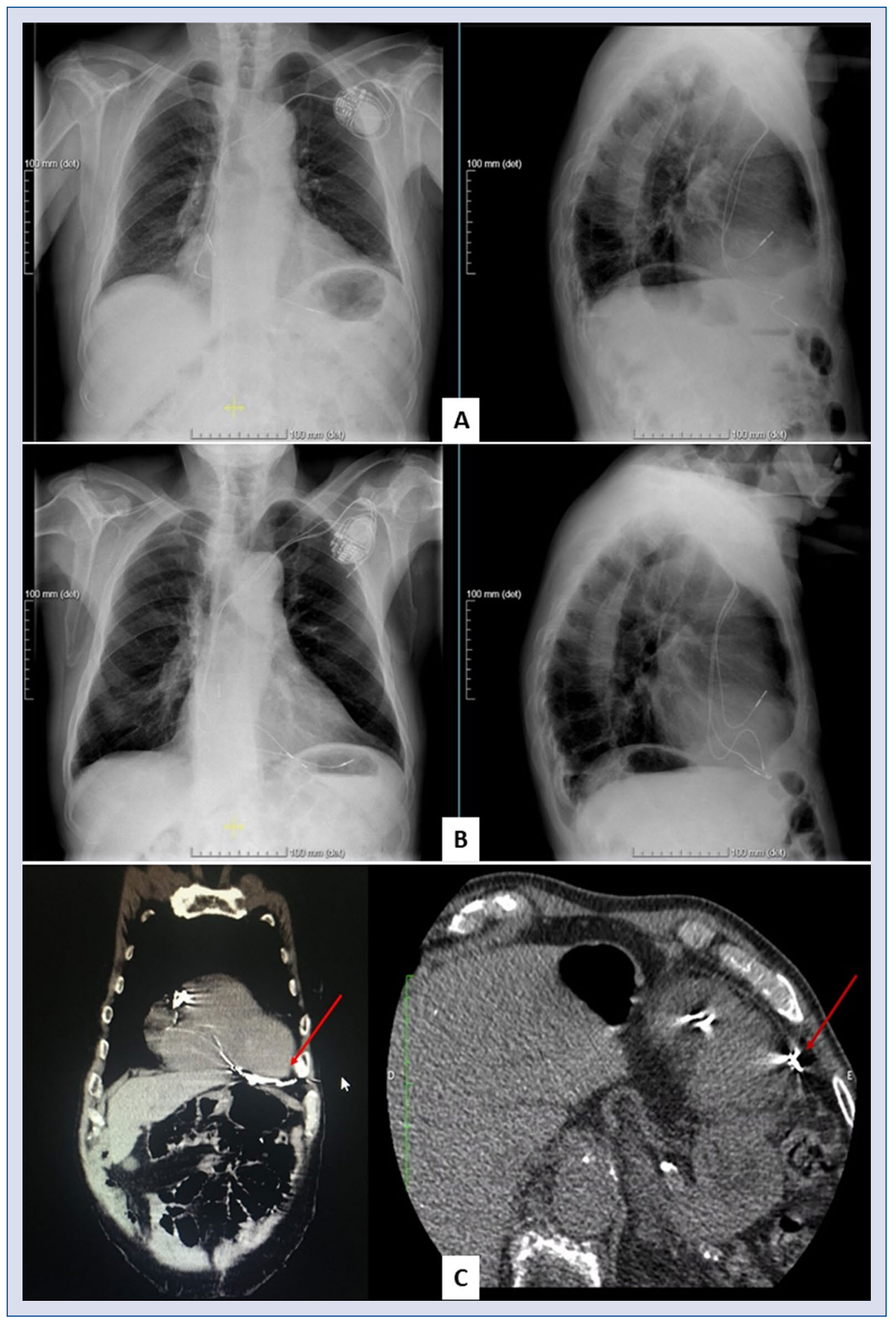

Figure 1. A. First implantation; on discharge date: thorax X-ray showing normal positioning of atrial and ventricular leads and absence of pleural complications; B. After surgical review, a new ventricular lead is implanted; on discharge date: thorax X-ray showing a new lead in normal position, and the old one displaced within the cardiac silhouette; C. Cardiac computed tomography: showing right ventricular apex perforation by a ventricular lead located beneath the left ventricle's inferior wall and apex (arrows). 